\title{
A ARTE DE BEM VIVER A PAISAGEM EM SEU TEMPO: MIRANDA MARTINELLI MAGNOLI E O ENSINO DE ARQUITETURA NO BRASIL
}

\section{THE ART OF THE COMPREENSION OF THE LANDSCAPE: MIRANDA MARTINELLI MAGNOLI AND THE ARCHITECTURE'S EDUCATION IN BRAZIL}

\section{Paulo Chiesa}

Professor doutor do curso de Arquitetura e Urbanismo e do Programa de Pós-Graduação em Educação da Universidade Federal do Paraná (UFPR).

E-mail: chiesa@ufpr.br 


\title{
RESUMO
}

O artigo aborda a contribuição da arquiteta Miranda Martinelli Magnoli para o estudo, o ensino e a prática de arquitetura no Brasil. Para isso, resgatam-se fragmentos de textos de sua autoria e investiga-se o rebatimento de suas idéias sobre o ambiente e a paisagem em três pesquisas por ela orientadas, que concluíram com a defesa de teses de doutorado na FAUUSP. Busca-se enfatizar, por esse tipo de análise, o aporte original dessa intelectual para compreender a dimensão cultural das paisagens, para além da noção corrente de paisagem como expressão singular de uma porção do ambiente ou, ainda, da paisagem como os espaços e lugares não-edificados residentes na arquitetura, nas cidades e no território.

Palavras-chave: Miranda Magnoli, ensino de arquitetura, cultura, paisagem e ambiente.

\begin{abstract}
This article emphasizes the contribution of architect and professor Miranda Martinelli Magnoli to the study, teaching and practice of architecture in Brazil. With broad and ethical approach to landscape as cultural fact, her professional and, specially, academic work has always reflected the vigorous defense of public spaces as means to improve existing cities and its living conditions with social justice and dignity. In order to illustrate Magnoli's ideas and her influence in teaching, planning and design, fragments of her writing and three doctoral dissertations, concluded under her supervision at FAUUSP, are analyzed and compared.
\end{abstract}

Key words: Miranda Magnoli, education in architecture, culture, landscape and environment. 


\title{
A ARTE DE BEM VIVER A PAISAGEM EM SEU TEMPO: MIRANDA MARTINELLI MAGNOLI E O ENSINO DE ARQUITETURA NO BRASIL
}

\author{
THE ART OF THE COMPREENSION OF THE \\ LANDSCAPE: MIRANDA MARTINELLI MAGNOLI AND THE \\ ARCHITECTURE'S EDUCATION IN BRAZIL
}

\section{Breves Palavras Iniciais}

O tempo e o espaço são elementos fundamentais em nossas vidas. A arquitetura sintetiza o tempo no espaço, por meio da arte e da técnica de intervir e construir edifícios, cidades e paisagens. Os conceitos de ambiente e paisagem, tal qual os manejamos atualmente, eram até pouco tempo desconhecidos nos cursos de arquitetura do Brasil; muito embora a moderna arquitetura brasileira tenha raízes na Semana de Arte Moderna de 1922 e tenha sido também motivada pelo resgate de aspectos da cultura e das paisagens nacionais ${ }^{1}$. Sabemos superficialmente quem foi Burle Marx e o significado de sua obra para o paisagismo contemporâneo. Reconhecemos a contribuição de seu legado para a valorização do desenho dos espaços livres, assim como para o estudo e uso da flora local em jardins nos vazios da arquitetura e da cidade. Porém, ainda há muito a descobrir sobre outros indivíduos, arquitetos ou não, que contribuíram na construção e consolidação de um espaço para a paisagem entre os saberes e práticas dos arquitetos e urbanistas.

O ensino de paisagismo nas escolas de arquitetura do Brasil foi sistematizado como área de conhecimento e grupo de disciplinas integradas ao ensino de arquitetura e urbanismo entre as décadas 1950 e 1980 na Faculdade de Arquitetura e Urbanismo da Universidade de São Paulo (FAUUSP). Simultaneamente, mudanças sociais e políticas transformaram radicalmente as formas de viver e ocupar o território. Os domínios do conhecimento humano evoluíram, expondo a complexa relação entre a diversidade de espécies e comunidades com seus ecossistemas. Novos e inusitados enfoques científicos integradores emergiram. Nesse contexto, é importante saber um pouco mais sobre a trajetória dos conceitos de ambiente e da paisagem no âmbito das escolas e comunidades de arquitetos brasileiros ${ }^{2}$.

Mesmo com o prejuízo que pode advir da omissão de muitos outros batalhadores neste artigo, cabe aqui focar a contribuição da arquiteta ítalo-paulista, doutora Miranda Martinelli Magnoli, para este processo. O presente trabalho nada mais é do que um croqui de uma das personagens fundamentais para a edificação dessa área de conhecimentos. Sem pretender pintar um quadro fiel à sua personalidade, polêmica e combativa, desde já reconheço e antecipo meus limites. Caberá complementá-lo a várias mãos e debates, buscando resgatar a memória e situar essa homenagem no domínio atemporal que a amizade e o respeito reservam àqueles os quais a conhecem e tiveram oportunidade de compartilhar suas idéias, lutas e ensinamentos. 


\section{Perfil Preliminar: A Personagem}

Miranda Magnoli é uma figura de seu tempo, inserida em uma sociedade em que "a cidade densamente construída é o lugar por excelência do espaço livre contemporâneo. É a esse espaço que cabe requalificar a cidade existente" (MAGNOLI. 1996, p. 13). Ela se questiona permanentemente e pergunta a todos: qual cidade e qual espaço são esses; como se projeta, usa-se e valoriza esses lugares? A noção clara da natureza, caráter e função dos espaços livres na história das civilizações, com um sólido conhecimento do que pensa e diz, é o que lhe permite jamais desvincular a intervenção humana em relação aos processos modeladores do território ${ }^{3}$. Está lançado o desafio de compreender paisagem como um fato social, como a própria cultura que precede e humaniza a espécie.

A trajetória pessoal e profissional da arquiteta Miranda Magnoli contribuiu para que, no Brasil, e especialmente a partir da FAUUSP, fosse sistematizado um conceito peculiar sobre a paisagem no contexto do ensino de arquitetura e urbanismo. A noção de paisagem defendida por Miranda Magnoli, portanto, emerge do homem e sua cultura, tendo como conteúdo e continente os processos sociais e sua interação dinâmica com o ambiente natural e humano, em um viés histórico e dialético ${ }^{4}$. Esse particular enquadramento das questões do ambiente e da paisagem resulta, por sua vez, da constante invocação da natureza relacionada às permanentes transformações científicas e tecnológicas imersas em conflitos sociais e territoriais, sem perder a perspectiva estética inerente à sua formação de arquiteta. A defesa de valores estéticos, nesse caso, articula-se a um claro posicionamento político e ético do que é essencial para a sociedade, em cada tempo e lugar 5 .

O território da arquitetura, a partir de suas idéias e postura profissional, alarga-se - ao invés de espremer-se entre as tendências de especialização verificadas na consolidação do campo profissional de arquitetura. Trata-se de um mercado de trabalho que se desenvolveu, nas últimas cinco décadas, sob profunda divisão social do trabalho com forte impacto sobre as tradicionais atividades de projeto (o desenho dos edifícios, dos objetos e interiores, da cidade e da paisagem). "As possibilidades de reformulação das cidades, por renovação de setores urbanos estão, na profissão, com os arquitetos que trabalham com o urbanismo, o planejamento, a edificação. Nós, arquitetos que lidamos com a paisagem, temos problemas muito sérios com a forma de compreensão e atuação da maioria daqueles arquitetos." (MAGNOLI, 1996, p. 17) Ou, ainda, que se consolidou recentemente em outras regiões do Brasil, sob os impactos provocados pela acelerada evolução dos meios técnicos e a acirrada concentração de renda em nossa sociedade. Os processos de urbanização e de metropolização da sociedade brasileira, com suas repercussões socioespaciais no território e na paisagem, são o cadinho cultural da reflexão sensível e inovadora de Miranda Magnoli.

Não poderia deixar de registrar que não deve ter sido simples - muito menos fácil - para uma arquiteta se afirmar na atividade profissional autônoma, ou como docente e pesquisadora de uma das mais importantes instituições de ensino do Brasil. Tendo em vista tanto o fato de o mercado de trabalho ser dominado pelos homens, assim como pelo nível complexo e exigente das tarefas e cargos que coube a ela desempenhar, "... por outro lado, também temos uma lacuna muito séria relacionada aos demais agentes de produção do espaço público, diretamente correlacionados com nosso projeto [...] não temos sido capazes de lidar corretamente com a participação de outras formações [...] de transformar nossas associações em instituições que, pela excelência do seu caráter científico, angariassem os créditos para aceitar, qualificar e conferir os papéis e dimensões adequadas a todas as diferentes contribuições" (MAGNOLI, 1996, p. 17). O caráter combativo de sua personalidade, sem dúvida, advém de suas origens e do pleno exercício do livre arbítrio nas condições adversas os quais marcam a sociedade brasileira contemporânea e, mais especificamente, o terreno e os caminhos por onde essa arquiteta transitou. 
Já a faceta polêmica da arquiteta resulta de um posicionamento muitas vezes solitário - e por isso radical - diante de um somatório de situações e acontecimentos, dos quais muito pouco participei. No entanto, se tivesse de intuir sobre as origens de sua postura exigente com relação ao trabalho, colegas e alunos, diria que emerge e nutre-se de uma perspectiva humana invejável. É fruto da indignação diante da desigualdade de condições de vida presente em nossa realidade, "uma concepção já clara em países que não querem aceitar a violência de milhões vivendo na pior miséria, em cidades mais conscientes dos benefícios decorrentes de um país mais justo, de um país com divisões mais tênues, de segregações menos indignas" (MAGNOLI, 1996, p. 13).

Essa postura expressa uma atitude até certo ponto estóica, que se fundamenta em relações estabelecidas com outros sujeitos, com suas idéias e histórias. Reflete também rigor intelectual e uma árdua disciplina aplicada em problematizar e verter seus conhecimentos para uma práxis coerente com o programa o qual defende - em síntese, o direito à autonomia e à liberdade individual diante de qualquer tipo de preconceito e opressão, "como clarificar as mentes na medida em que as classes médias euforicamente perseguem o consumismo, apesar de um quadro em que a pobreza é imensa, em que é contínuo o agravamento da distribuição de renda. Talvez esta seja a única desigualdade aceita com cada vez mais crescente naturalidade ou, pelo menos, com cada vez menos indignação" (MAGNOLI, 1996, p. 16).

Ou seja, Miranda Magnoli é fruto de condições objetivas e subjetivas historicamente datadas em um contexto tumultuado da conjuntura política e social da sociedade paulista e nacional. Uma figura de seu tempo, que no espaço o qual lhe coube desempenhou suas funções cultivando um profundo sentimento de respeito pelo ser humano e sua cultura, cerzindo o conceito de paisagem e ambiente a partir dos tênues fios os quais conformam o tecido democrático de uma sociedade excludente, injusta com seu povo e desrespeitosa com o ambiente social e natural. Todavia, alguém que sabe bem perceber, sonhar e viver a paisagem em seu tempo ${ }^{6}$.

\section{Aspectos da Relação Profissional Acadêmica}

Seria difícil continuar nessa linha de argumentação, devido aos problemas de manter isenção ao descrever uma personalidade tão viva e complexa a qual, com maior ou menor intensidade, é referência para muitos arquitetos, urbanistas e paisagistas. Por isso, é necessário estabelecer mediações, à maneira dos antropólogos no exercício etnográfico. Se questionado, a partir de agora, sobre quem é Miranda Magnoli, responderia: não sei e nunca precisei de explicações para ser seu orientando, amigo e parceiro. Porém, é impossível deixar de reconhecer sua dedicação e profissionalismo na construção de novos professores e pesquisadores, a exemplo do que se relata a seguir.

Fui seu orientando no programa de pós-graduação da FAUUSP de 1997 até 2001, quando iniciei e concluí meu doutorado nesta instituição. De lá para cá, apesar da distância de 400 quilômetros, dedico-me a alimentar essa amizade e relação profissional; é verdade que bem menos do que desejaria. Uma nova etapa desse relacionamento nasceu a partir do convite para participar de banca de doutoramento de outro orientando seu, o arquiteto Emmanuel Antonio dos Santos (2002). Tal fato ocorreu apenas alguns meses após a conclusão de meu próprio trabalho. Destaco essa deferência não apenas como um voto de confiança ou de escolha balizada pela relação pessoal. Mas como investimento na formação de um jovem ou recente doutor, uma prática saudável e ao mesmo tempo desafiadora diante da responsabilidade de compartilhar desse momento com outros doutores experientes, correspondendo às exigências postas pelo tema, pelo trabalho e pela banca julgadora. No ano seguinte, ministrei palestra sobre a paisagem e o planejamento urbano de Curitiba em curso de extensão organizado pelo Instituto Superior de Estudos Avançados da USP, por sua indicação. Nesse mesmo período dividi com Eugenio Queiroga módulo de sua disciplina na pós-graduação, abordando aspectos da paisagem em transformação na região metropolitana de Curitiba (2003). Finalmente, compareci à banca de defesa de doutorado do arquiteto Sun Alex (2004), também orientando seu. 
O sentido de citar a participação nessas situações da vida acadêmica é apoiar a estratégia que dá seqüência a esse texto. Por um lado, revela, como dito antes, o investimento deliberado na formação continuada de professores e pesquisadores. Por outro aspecto, deve-se registrar que esse tipo de prática produz ganhos qualitativos para recém-doutores, à medida que: a) permite acesso em primeira mão às pesquisas, dissertações de mestrado e teses de doutorado - um verdadeiro privilégio, se bem aproveitado, porque nem sempre esses trabalhos são publicados; b) obriga-os a estruturar suas argüições, elaborar critérios e questões reforçando o campo de discussões críticas sobre saberes referentes ao ambiente e à paisagem; c) exercita a postura e técnica discursiva dos participantes, agrega-lhes autoconfiança e desenvolve o espírito construtivo diante de impasses e defeitos os quais geralmente ocorrem na conclusão de trabalhos desenvolvidos com diferentes empenhos e limitações pelos próprios candidatos; d) finalmente, mantém os ex-orientadores e seus orientados próximos e ligados ao debate vivo do núcleo original de formação, promovendo encontros com outros colegas docentes e abrindo perspectivas para participação em outras atividades, tais como novas bancas, seminários, pesquisas, etc.

Enfim, estimular a participação de recém-doutores em bancas de defesa e outras atividades acadêmicas correlatas significa apoiar o processo de formação permanente desses docentes e, como diria Jorge O. Caron, contribuir para "aprender a ensinar" (MAGNOLI, 1996, p. 2 ). Ao mesmo tempo, representa a valorização de um comportamento coletivo diante da carreira acadêmica, em momentos cruciais da cultura de uma escola de arquitetura ${ }^{7}$. Devido ao caráter de ritual de passagem com que se entende esse momento do cotidiano acadêmico, por meio dele se renova o pertencimento à escola e seu programa de formação; além de incitar o espírito crítico e promover a troca de saberes. É importante destacar o investimento pedagógico realizado pela arquiteta Miranda Magnoli - uma aposta consciente na profissionalização do ensino e da pesquisa em arquitetura ${ }^{8}$.

\section{Aspectos da Construção e Transmissão de Saberes}

Tendo exposto a dimensão formativa que envolve as bancas de doutorado, cabe destilar dessas experiências o debatido sobre a paisagem e o ambiente a partir das três pesquisas de doutoramento aqui citadas. A análise proposta inclui também a tese realizada por este autor, uma vez que ela foi integralmente discutida e orientada pela arquiteta Magnoli. Seria mais interessante realizar essa reflexão em conjunto com os demais colegas, Emmanuel e Sun. Porém, na impossibilidade de isso ocorrer, resta ter participado de suas bancas e o fato de refletir que talvez essas questões não viessem à luz de outra forma. Nenhum desses três trabalhos foi publicado, nem ainda resultaram em artigos contemplando o todo ou suas partes ${ }^{9}$.

A aposta a qual se faz é que eles expressam um programa de questões coerentes entre si e que, apesar de refletirem as opções de cada pesquisador, enfeixam um conjunto de temas e problemas sintonizados com a orientação de Miranda Magnoli. Com isso não se está minimizando o esforço criativo e individual de nenhum dos colegas ou da própria. Muito pelo contrário, está fora de questão que as teses refletem a opinião de seus autores. $O$ importante agora é estabelecer a ponte entre essas pesquisas (temas, objetivos, enfoques, resultados) e a maneira original, sistêmica e integrada de Miranda Magnoli compreender a arquitetura, a cidade e a paisagem no ambiente e cultura de nossa época, "na realidade, pretendia-se criar condições para um novo arcabouço conceitual em que nosso tempo e nosso espaço eram fundamentais" (MAGNOLI, 2004, p. 1). A tabela a seguir foi construída com o objetivo de sintetizar as principais questões investigadas nessas teses e permitir uma visão comparada da temática geral e específica de cada uma delas. Ainda que corra o risco de simplificar e reduzir aspectos complexos das opções e dos enfoques metodológicos empregados pelos pesquisadores, ela pode ser útil para expor os conceitos os quais permitem navegar entre e pelas reflexões desses autores, e fundeá-los no pensamento de Miranda Magnoli. 
Tabela esquemática das pesquisas de CHIESA, P.; SANTOS, E. A. dos; ALEX, Sun

\begin{tabular}{|c|c|c|c|}
\hline Autores & CHIESA, P. & SANTOS, E. A. dos & ALEX, Sun \\
\hline Título & $\begin{array}{l}\text { O desenho como desígnio: } \\
\text { por uma ética do risco }\end{array}$ & $\begin{array}{l}\text { As paisagens do plano e } \\
\text { os planos da paisagem: da } \\
\text { paisagem no planejamento } \\
\text { ao planejamento com a } \\
\text { paisagem }\end{array}$ & $\begin{array}{l}\text { Convívio e exclusão no } \\
\text { espaço público: questões } \\
\text { de projeto de praça }\end{array}$ \\
\hline Temática geral & $\begin{array}{l}\text { A tradição de ensino de } \\
\text { arquitetura no Brasil e a } \\
\text { contribuição da escola de } \\
\text { arquitetura e dos arquitetos } \\
\text { para a modernização da } \\
\text { cidade de Curitiba }\end{array}$ & $\begin{array}{l}\text { A questão ambiental e social } \\
\text { relacionada ao planejamento } \\
\text { urbano e à prática de elabo- } \\
\text { rar planos diretores para as } \\
\text { cidades }\end{array}$ & $\begin{array}{l}\text { O projeto de praças como } \\
\text { lugares de convívio social } \\
\text { cotidiano e articulação do } \\
\text { tecido urbano }\end{array}$ \\
\hline Temática específica & $\begin{array}{l}\text { Arquitetura como: arte e } \\
\text { técnica; e a complexa integra- } \\
\text { ção dos conhecimentos sobre } \\
\text { os edifícios, as cidades e as } \\
\text { paisagens }\end{array}$ & $\begin{array}{l}\text { A incorporação dos conceitos } \\
\text { de ambiente e paisagem na } \\
\text { prática de planejamento e } \\
\text { nos processos de elaboração } \\
\text { de planos diretores }\end{array}$ & $\begin{array}{l}\text { O paisagismo moderno e } \\
\text { os novos desenhos e usos } \\
\text { do espaço público como } \\
\text { antídotos da vida urbana e } \\
\text { sua tradição democrática }\end{array}$ \\
\hline $\begin{array}{l}\text { Enfoque } \\
\text { metodológico }\end{array}$ & $\begin{array}{l}\text { Estudo do processo de } \\
\text { transmissão cultural realizado } \\
\text { pela escola e pelo professor } \\
\text { na construção de disciplinas } \\
\text { acadêmicas; a paisagem } \\
\text { incorporada ao ensino de } \\
\text { arquitetura e do processo de } \\
\text { urbanização de Curitiba }\end{array}$ & $\begin{array}{l}\text { Estudo dos diversos planos } \\
\text { históricos e culturais da } \\
\text { paisagem e sua incorporação } \\
\text { conceitual e metodológica } \\
\text { nos processos de planeja- } \\
\text { mento e de elaboração do } \\
\text { plano diretor }\end{array}$ & $\begin{array}{l}\text { Estudo dos projetos de } \\
\text { praças na tradição do } \\
\text { paisagismo europeu e } \\
\text { dos EUA, adotados como } \\
\text { marco referencial para a } \\
\text { avaliação pós-ocupação } \\
\text { de projetos de praças } \\
\text { recentes do Brasil }\end{array}$ \\
\hline $\begin{array}{l}\text { Conceitos e } \\
\text { categorias de análise }\end{array}$ & $\begin{array}{l}\text { Cultura; educação; ensino; } \\
\text { disciplinas acadêmicas; } \\
\text { ambiente; paisagem; cidade; } \\
\text { metrópole; desenho; ensino } \\
\text { de projeto integrado }\end{array}$ & $\begin{array}{l}\text { Cultura; ambiente; paisagem; } \\
\text { território; processo de urbani- } \\
\text { zação; planejamento urbano; } \\
\text { plano diretor; integração } \\
\text { disciplinar; métodos e escalas } \\
\text { da paisagem }\end{array}$ & $\begin{array}{l}\text { Cultura; paisagem; espa- } \\
\text { ços livres públicos; praças; } \\
\text { identidade; diversidade; } \\
\text { usos e práticas sociais; } \\
\text { inclusão e exclusão social; } \\
\text { categorias e escalas de } \\
\text { projeto; desenho }\end{array}$ \\
\hline $\begin{array}{l}\text { Referências } \\
\text { contextuais }\end{array}$ & $\begin{array}{l}\text { O planejamento urbano e a } \\
\text { escola de Curitiba/PR }\end{array}$ & $\begin{array}{l}\text { O plano diretor de São José } \\
\text { dos Campos/SP }\end{array}$ & $\begin{array}{l}\text { Seis praças do centro de } \\
\text { São Paulo/SP }\end{array}$ \\
\hline Conclusões & $\begin{array}{l}\text { Sustenta que o ensino de } \\
\text { arquitetura deve ser conside- } \\
\text { rado como um trabalho social } \\
\text { específico e exigente, tanto } \\
\text { ético quanto profissional. } \\
\text { Defende a idéia que a escola } \\
\text { deve estruturar e planejar o } \\
\text { processo de ensino e apren- } \\
\text { dizagem a partir da realidade } \\
\text { física e social do ambiente } \\
\text { onde ela se insere. Defende } \\
\text { ainda que se aprende arqui- } \\
\text { tetura desenhando-a, e, por- } \\
\text { tanto, o processo de desenho } \\
\text { sintetiza o método específico } \\
\text { da disciplina Arquitetura. }\end{array}$ & $\begin{array}{l}\text { Entende que a efetiva e } \\
\text { concreta incorporação dos } \\
\text { elementos do meio natural } \\
\text { e com relativo grau de natu- } \\
\text { rança no processo de pensar } \\
\text { o planejamento urbano e } \\
\text { de promover a urbanização } \\
\text { pode contribuir para obter } \\
\text { um meio urbano mais equili- } \\
\text { brado, mais justo e diversifi- } \\
\text { cado no uso dos recursos da } \\
\text { natureza dos/nos espaços, } \\
\text { com paisagens mais inte- } \\
\text { gradas e integradoras e de } \\
\text { maior qualidade de desenho } \\
\text { dos espaços, especialmente } \\
\text { aqueles de uso público. }\end{array}$ & $\begin{array}{l}\text { Conclui que nas seis pra- } \\
\text { ças estudadas do centro de } \\
\text { São Paulo há: } \\
\text { a) desvinculação entre as } \\
\text { praças e os entornos; } \\
\text { b) ausência de manutenção } \\
\text { e adaptações sistemáticas; } \\
\text { c) domínio do urbanismo } \\
\text { rodoviário e da engenharia } \\
\text { de tráfego; } \\
\text { d) ênfase no design ou na } \\
\text { jardinagem em detrimento } \\
\text { do convívio social; } \\
\text { e) influência do paisagismo } \\
\text { dos EUA a partir dos anos } \\
1960 \text {. }\end{array}$ \\
\hline $\begin{array}{l}\text { Local e ano de } \\
\text { defesa }\end{array}$ & FAUUSP: 2001 & FAUUSP: 2002 & FAUUSP: 2004 \\
\hline
\end{tabular}

Fonte: Teses de doutorado dos autores citados. Curitiba, 2006 
A confecção desse e de qualquer quadro esquemático contém grande dose de arbitrariedade. Contudo, como foi dito, ele pode ser útil enquanto "mapa de navegação" para viajar entre as três pesquisas realizadas, aparentemente, sem conexão entre si. Esse roteiro abstrato carece de um diário de bordo ou de "portulanos", como definiu Alberto Cordiviola: "... não é difícil admitir que cada tipo de viagem possui suas ferramentas adequadas [...] os portulanos, herdeiros dos 'périplos' gregos e romanos, deram todo o conhecimento da crescente navegação do segundo milênio enquanto a cartografia descrevia o paraíso e o inferno e os perigos da vida terrena" (CORDIVIOLA, 2005, p. 25) ${ }^{10}$.

primeiro aspecto comum a elas é o desdobramento dos temas de cada pesquisador em torno dos problemas atinentes à paisagem e ao ambiente. Por outro lado, ainda que as temáticas de pesquisa partam de trajetórias pessoais e interesses específicos desses pesquisadores, como dito, elas fazem parte de um programa o qual configura uma linha de pesquisas. Por isso, quando vistas em conjunto, traduzem as preocupações de uma área de conhecimento em construção no domínio da paisagem e do ambiente argüido por arquitetos. Como se sabe, não é simples nem fácil delimitar um tema de pesquisa. Uma tese de doutoramento, não raro, dá continuidade a uma dissertação de mestrado. Quando, e se isso ocorre, novas questões são identificadas e aprofundadas em níveis e escalas distintos. Porém, das três, apenas a segunda pesquisa possui essa característica. As demais possuem, evidentemente, traços de trabalhos e preocupações anteriores de seus autores, mas não foi o essencial para a escolha e recorte dos temas abordados.

\section{Pesquisa 01}

No primeiro trabalho as transformações na paisagem de Curitiba constituem a chave para descrever e compreender a incidência de um consistente processo de urbanização que tomou forma e conteúdo na história recente do Paraná moderno, a partir da segunda metade do século passado. Esse processo de mudança tem um componente singular - o planejamento urbano - apontado como responsável pelo êxito dessa cidade em conduzir e monitorar seu processo de urbanização. No entanto, essa explicação só encontra sentido se vinculada a fatores situados em outras escalas temporais, espaciais e culturais. É a história do desenvolvimento econômico e social do território paranaense que explica o intenso deslocamento de pessoas e capitais a concentrarem-se em Curitiba. Por outro lado, foi a presença e a continuidade de instituições e pessoas (com saberes específicos) as quais qualificaram e conduziram esses processos de modernização. Emerge desse fato a participação destacada de arquitetos e urbanistas, quer seja pela escola de arquitetura (CAUUFPR) quer seja por órgãos públicos de planejamento e projeto urbano (IPPUC). No intervalo das últimas duas décadas do século, a urbanização do território já se verifica em escala regional e metropolitana - exigindo considerar também relações escalares mais amplas e sistêmicas dos espaços urbanizados com a base natural, com o processo histórico, as populações e atividades econômicas e sociais que se desenvolvem na periferia e nas regiões vizinhas de Curitiba. O CAUUFPR e o IPPUC se distanciam e cada qual gesta "doutrinas" e modos de investigar, perceber e atuar a partir e no espaço - tendo no desenho/projeto o método de estudo, reflexão e síntese do discurso e linguagem da arquitetura e do urbanismo local. $O$ trabalho problematiza também a contribuição de diferentes tradições e seus saberes na composição de um novo modo de sentir, perceber e fruir o ambiente urbano. A identidade da população curitibana com sua cidade se fez por meio do processo de transformação e modernização dos espaços e serviços públicos: o transporte; o sistema viário; o patrimônio natural e edificado preservado; os equipamentos sociais; os espaços livres vegetados ou não; a consciência ecológica difundida em um contexto de apropriação e modificação das formas de usar e apropriar-se do território; etc. Essa dimensão da cultura urbana local, tendo na paisagem e no ambiente novos significados e valores, é o que permite compreender a particularidade dessa experiência. $O$ resultado final deste trabalho reflete como se ensina 
arquitetura, levando-se em conta tais questões na estruturação de disciplinas acadêmicas de projeto integrando o edifício, a cidade e a paisagem, "discutir o ensino caracterizando o processo de desenho como síntese do método específico da disciplina" (MAGNOLI, 2004, p. 12). O desenho é a outra face do olhar, conclui a pesquisa. $E$, "... se esse olhar é fruto de um raciocínio crítico e criativo, quanto mais largo o campo de análise e reflexão do arquiteto sobre o território, melhores serão as possibilidades de identificar as condições e relações que contribuem na sua formação e desenvolvimento" (CHIESA, 2001, p. 114).

\section{Pesquisa 02}

Nessa outra pesquisa, a história da ocupação e da recente experiência de planejamento urbano da cidade de São José dos Campos constituiu o próprio cotidiano do pesquisador, o qual baseou sua intervenção como coordenador das atividades do plano diretor em sua dissertação de mestrado, "... analisam-se experiências concretas, pouco usuais na prática do arquiteto que trabalha com a paisagem e o ambiente [...] a tese expõe a reflexão à luz dessa experiência concreta: o Estado, o poder local, o município no território, são aspectos que fazem parte das questões sociedade, cidadania, participação, gestão e se manifesta no Plano" (MAGNOLI, 2004, p. 12). O argumento central se assenta sobre duas premissas: a questão social e a ambiental se entrecruzam no processo de planejamento, expressas pelo desejo de mudança da sociedade naquele momento; e o processo de elaboração dos planos diretores pode e deve incorporar a paisagem como conteúdo operacional para a adequada formulação de estratégicas, prescrições e projetos capazes de qualificar e conduzir o processo de desenvolvimento urbano do município. Ocorre que essa paisagem precisa ser investigada, percebida, analisada e diagnosticada. A paisagem, portanto, possui caráter histórico, social e ambiental, exigindo instrumentos teóricos e metodológicos apropriados, os quais contemplem e operem com diferentes camadas do tempo e sobre distintas escalas de abrangência e níveis de aprofundamento das informações buscadas, obtidas e produzidas. Resulta disso a ênfase depositada sobre "os planos da paisagem e as paisagens do plano", com os quais técnicos e população precisam conhecer e lidar. Novamente o conceito de ambiente e paisagem cobra do autor um entendimento amplo, integrado e integrador das relações entre o todo e as partes desse processo analítico e dessa realidade em transformação, "... se a parte contém o todo, pode-se então dizer que o inverso também é verdadeiro, portanto, quando se pensa que ao organizar-se a totalidade de uma dada paisagem está-se fazendo-o com independência e com isenção em relação às questões referentes. Às suas partes e/ou particularidades, incorre-se em um equívoco de origem. Nesse sentido, entende-se que o todo organizado é formado pela articulação de um conjunto de partes e/ou particularidades que se organiza em estreita correspondência com a totalidade" (SANTOS, 2002, p. 25-26). O propósito é compreender como se trabalha com as diferentes camadas da história e da cultura, articuladas entre si - de modo a promover a consideração da paisagem e do ambiente como valores na construção de uma idéia de plano diretor, tão atento ao social como ao natural, "... de alguma maneira geral não é possível estabelecer um todo organizado, sem pensar simultaneamente na organização das partes e/ou particularidades, acreditando-se que só é possível atingir organizações consistentes de totalidades e particularidades quando essas dizem respeito às questões de urbanização, ao se adotar uma abordagem em que a aproximação do objeto se faça em um movimento pendular. Isto é, fazendo o trânsito o tempo todo do geral para o particular e dialeticamente retornando do particular para o geral, num continuum que pelas suas peculiaridades intrínsecas pressupõe se colocar as questões em relação ao todo e ao particular sempre e necessariamente de modo simultâneo" (SANTOS, 2002 , p. 26). A contribuição dessa pesquisa, nesse sentido, está em responder se partimos do geral para a particular ou, o inverso disso, na abordagem das escalas referenciais do sítio, do urbano e da região. Segundo o autor, para se enfrentar os planos da paisagem 
em uma totalidade integrada e integradora, "... essa aproximação e afastamento passam a ser movimentos dotado de um mesmo e único olhar, pois que a aproximação é realizada sob o pano de fundo do que se percebeu durante o afastamento, do mesmo modo que o afastamento traz consigo os elementos de aproximação" (SANTOS, 2002, p. 26). Como diria Magnoli, simultaneamente estamos indo e vindo, em um movimento pendular, entre essas diferentes escalas de estudo e abordagem da realidade.

\section{Pesquisa 03}

A terceira pesquisa estuda o projeto de praças como lugares de convívio social cotidiano e articulação do tecido urbano a partir das mudanças no tempo e forma de apropriação desse espaço, "... tratada como entidade paisagística, a praça contemporânea ganhou relevância ambiental com o domínio do pensamento higienista sobre o desenho da cidade industrial e com a valorização do verde na implantação da arquitetura moderna. Com o desenvolvimento das disciplinas de paisagismo e planejamento urbano, a praça passou também a ser vista como equipamento recreativo e elemento integrante do sistema de espaços livres da cidade, abrandando assim as distinções nítidas entre outras formas de uso do espaço público, como jardins e parques" (ALEX, 2004 , p. 11). Ao problematizar essa tendência, o autor resgata a praça e seu caráter público e societário no modo de vida urbano. Local do mercado, abrigo de festividades e cerimônias, de celebrações, de encontros e desencontros, fatos sociais que lhe exigiram um alto nível de síntese por intermédio do projeto, do desenho e do detalhamento de seus elementos construtivos. Os diferentes níveis históricos e simbólicos desse espaço articulador da vida social nas cidades não escapam ao autor. Para cada povo, uma praça, cada praça em seu espaço, tempo e cultura. A relação das praças com seu entorno, e com os modos de vivenciá-los em cada sociedade e cultura, imprimem mudanças no desenho, na forma, na articulação do programa com seu entorno, valores e hábitos sociais, bem como na presença e ausência de elementos que lhes conferem escala urbana e humana, "... é hipótese desse trabalho que os projetos de praças, ao enfatizar o 'recreacionismo' e o 'verdismo' preconizados pelo paisagismo moderno, esvaziaram sua função primordial de articulação do tecido urbano" (ALEX, 2004, p. 11). Para verificar a validade de suas hipóteses, o autor estudou e analisou a genealogia e trajetória de praças emblemáticas, bem como de releituras a partir de movimentos filosóficos e urbanísticos que informaram as políticas públicas e o desenho dos espaços de uso público ao longo de séculos, até chegarem ao Brasil. Verificou também como os saberes advindos dessas praças comparecem no programa e desenho de outros tipos de espaços livres, tais como parques, tecidos urbanizados, shopping centers, etc., diante de novas formas de uso e consumo que caracterizam as sociedades urbanas atuais. Revelaram-se as mudanças entre cada continente, época e sociedade. Por fim, identificou distintas fases no processo de incorporação dessa tradição aos movimentos culturais e sociais os quais influíram na condução do processo de urbanização nos EUA - o parque fora da cidade ou ainda o fenômeno suburbano - informando o moderno paisagismo norte-americano, referente para a construção de saberes disciplinares presentes hoje em dia em nossa área. Não fugindo aos propósitos de avaliar o que está ocorrendo com esse tipo de espaço na atualidade e no Brasil, o autor produziu extenso trabalho de pesquisa sobre seis praças, seus projetos originais e suas reformas atuais, localizadas na área central da metrópole paulista: Largo do Arouche; Dom José Gaspar/1944; Franklin Roosevelt/1970; Liberdade/1975; Santa Cecília/1983; e Júlio Prestes/1999. Foi por meio de sucessivos desenhos em diferentes escalas, densamente elaborados e utilizados junto do texto, que o autor estabeleceu sua crítica, "... em São Paulo, há várias praças que, apesar dessa denominação e do tratamento paisagístico, acentuaram a fragmentação do espaço urbano, tornando-se uma barreira para as travessias ou um local ameaçador, evitado pela população" (ALEX, 2004, p. 11), e apresentou alternativas de projeto permitindo restabelecer, de novo, o papel central da praça em relação à arquitetura e à paisagem, "propõe alternativas para ampliar seu espaço de convívio social por meio de desenhos mais convidativos e adaptáveis 
que privilegiem o acesso, a integração com o entorno e a articulação com o tecido urbano [...] o pressuposto é de que o convívio social no espaço público está intimamente relacionado às oportunidades de acesso e uso, o que depende de um desenho 'interno' coerente e de um desenho 'externo' - as ruas e o tráfego da área - adequado. A articulação com o tecido urbano, isto é, a conexão entre espaços urbanos variados, da praça e do entorno, é uma das suas funções originais e essenciais" (ALEX, 2004, p. 105). As conclusões da pesquisa não precisam ser relatadas, porque saltam pela qualidade e força dos desenhos elaborados pelo autor e suas imagens de referência, "... a maioria das praças modernas encontra-se em situações tão deploráveis que podem ser consideradas anti-sociais ou mesmo 'anti-praças'. A pesquisa sustenta a tese de que os projetos inspirados no paisagismo moderno preocupam-se apenas com o uso, sem levar em conta o acesso e a integração com o entorno e que, ao enfatizar a ruptura estética, reforçaram a fragmentação do tecido urbano" (ALEX, 2004, p. 105). Dessa maneira, a tese adquire o caráter de manifesto contra a maneira displicente com que se assumem valores contraditórios às formas de vida da população usuária desses espaços. Ao mesmo tempo, alerta as autoridades e arquitetos sobre a responsabilidade de elaborar um bom desenho. $O$ povo lastima a privatização que os exclui de seus autênticos espaços democráticos. A sociedade perde, porque maus projetos inibem ou impedem a sociabilidade. E, com isso, a democracia imposta é a definida pelos projetistas e por aqueles com o poder de tomar decisões sobre o destino desses espaços - quase sempre desinformados sobre o que, de fato, são e para que servem as praças em nossas vidas.

\section{Quid Tum? ${ }^{11}$}

Espera-se ter evidenciado com esse ensaio a contribuição da arquiteta Miranda Magnoli à área de estudos do ambiente e da paisagem, bem como o rebatimento de suas idéias nas três pesquisas apresentadas. Cabe ao próprio leitor estabelecer outras relações entre elas, verificando sua atualidade e utilidade para continuar o programa de investigação aqui esboçado. E agora, o que fazemos? Agradecer sua presença entre nós. Reler seus textos e questioná-los à luz de nossas próprias preocupações. Interpretar o mundo que se gesta hoje com base nas questões as quais, tão apropriadamente, essa arquiteta soube articular ao seu modo de perceber, valorizar, refletir e intervir para compreender e modificar seus desdobramentos futuros. A arte de bem viver a paisagem em nosso tempo assume outros significados se tivermos aprendido suas lições. Entre elas, a que ainda há muito para se fazer juntos - se sabemos aonde ir.

\section{Notas}

(1) Maria Angela F. P. Leite, em sua tese de doutorado, sistematizou esses avanços: "A paisagem é resultado do equilíbrio entre múltiplas forças e processos temporais e espaciais. Em certa medida, a paisagem é um reflexo da visão social do sistema produtivo e suas formas transformam-se ou desaparecem sempre que as teorias, filosofias e necessidades que as criaram não são mais reais ou auto-evidentes. A percepção do tempo, do espaço e da natureza muda com a evolução cultural, o que exige a procura de novas formas de organização do território que melhor expressem o universo contemporâneo, formas que capturem o conhecimento, as crenças, os propósitos e os valores da sociedade." (LEITE, 1994, p. 7) Por outro lado, vale aqui a observação de Alberto Cordiviola: "... conceitos com alto teor de síntese constituem instrumentos poderosos para o domínio da relação do homem com a sociedade e com a natureza não humana [...] estes conceitos passam a ser operadores culturais, ao serviço da estrutura de poder dessa mesma cultura. Não podemos modelar noções cuja explicação desconhecemos. Noções como irreversibilidade, simultaneidade, futuro e tantas outras relacionados ao conceito de tempo estão prenhes de intenções e poderes" (CORDIVIOLA, 2005, p. 294).

(2) Miranda Magnoli identifica quatro períodos na trajetória do ensino de Paisagismo na FAUUSP, entre 1952 e 1981 : a) Em 1948, a criação da FAUUSP incluiu em sua programação didática a área de conhecimento referente à paisagem, resultando na criação da disciplina de Arquitetura Paisagística pelo jovem paisagista americano Roberto Coelho Cardozo, em 1952; b) A disciplina, desde 1952, seria parte do programa de planejamento territorial e a prática profissional era o elemento fundamental que alimentava o ensino das faculdades. $\bigcirc$ ensino de arquitetura se centrava, então, no estudo do edifício, enquadrado em um ambiente urbano que já iniciava seu adensamento caótico. Quando, em 1962, a FAUUSP passou por completa reformulação didática, o ensino de Paisagismo se 
manteve na seqüência de Planejamento. A partir de 1969 a disciplina passou a ser conduzida pelo arquiteto Antonio Augusto de Azevedo Antunes, com a colaboração de Daisy Igel (1954-57) e de Rodolfo Almeida Fernandes (1957-67); c) O período de 1970 a 1973, época tumultuada por intensas agitações e crises, culminou com a inserção da disciplina na área de Projeto da FAUUSP. Em 1973, Miranda Magnoli passou a integrar a equipe do professor Antunes que se retirou em 1974; d) O próximo período até 1981 foi de reformulação dos programas didáticos, contextualizando o ensino de Paisagismo com as questões emergentes dos vários movimentos sociais e ecológicos. Em fins de 1976 a disciplina possuía seis docentes em sua equipe e, em 1978, a FAUUSP iniciou Programa de Pesquisas - do qual a área participaria ativamente. Após 1974, novo enquadramento teórico e metodológico permitiu adaptar o ensino a um número crescente de alunos, incorporar o debate sobre a problemática dos povos do Terceiro Mundo, focar os estudos sobre os espaços livres públicos de uso coletivo e aprofundar o conhecimento sobre os problemas da paisagem (MAGNOLI, 1981, p. 56-76).

Um novo período pode ser compreendido a partir desse último até o presente, caracterizado pela sistematização e aperfeiçoamento do ensino na graduação - fortemente influenciado pelos resultados das pesquisas realizadas na pós-graduação -, cujo elenco e resumo do acervo de 1973 a 2003 foi tema de artigo publicado por Fany Cutcher Galender no número 17 da Revista Paisagem Ambiente: Ensaios. Magnoli, em artigo ainda inédito, traçou um esboço preliminar a respeito das experiências de pesquisa em Paisagem e Ambiente realizadas no âmbito do Programa de Pós-Graduação da FAUUSP pelo Grupo de Disciplinas Paisagem e Ambiente, no período 1973-2004. ... "a produção científica relatada limita-se à esfera da pós - sentido restrito, dissertações e teses. São aproximadamente 60 trabalhos; guardam o caráter acadêmico que institucionalizou esse nível de ensino superior na USP; a FAUUSP organizou o programa de pós-graduação a partir de uma única área de concentração: Estruturas Ambientais Urbanas; as pesquisas foram elaboradas com os parâmetros decorrentes desta condição de programa sem áreas específicas. A seleção de temas e as abordagens foram sempre opções espontâneas dos pósgraduandos. O objetivo prioritário em nossa área, durante o período em referência, foi realimentar as disciplinas de graduação, criando e elaborando matéria crítica para o ensino visto se considerar que vários eram os aspectos a atualizar, a reexaminar e ponderar em relação à época em que a disciplina havia se implantado, na década de 1950. Na realidade pretendíamos criar condições para um novo arcabouço conceitual em que nosso espaço e nosso tempo eram fundamentais" (MAGNOLI, 2004, p. 1).

(3) A expressão "sólido conhecimento do que pensa e diz" refere-se ao sentimento que se tem quando se está diante de alguém que torna uma simples conversa ou uma aula algo denso e instigante. $\bigcirc$ encontro ou o diálogo com essas pessoas fica marcado na memória, ensina e faz-nos refletir sobre muitos aspectos de nossas próprias vidas - fornecendo referenciais importantes, verdadeiras trocas culturais. É importante refletir sobre esse tema abordado na sociologia da educação por Pierre Bourdieu a partir da diferença entre herança cultural e repertório. Segundo Pierre Bourdieu, herança cultural é a bagagem trazida do convívio familiar, grupal ou social (tudo aquilo que nos precede e informa-nos), enquanto o repertório de cada um de nós, mestres e alunos, processa-se permanentemente a partir tanto de experiências advindas do sistema escolar formal quanto do exercício profissional e de nosso cotidiano. Nesse sentido, Miranda Magnoli responde tanto à sua origem latina e mediterrânea transladada ao Brasil e articulada a formação familiar, escolar e acadêmica recebida, quanto às experiências construídas em torno a seus interesses pessoais e profissionais. Todos esses elementos estão imbricados em um sistema de valores referentes à natureza e o papel dos espaços livres públicos para as sociedades, no passado e na atualidade.

(4) O antropólogo José Marcio Barros nos incita a refletir sobre cultura não em seu sentido exclusivo, "... como sinônimo de sofisticação e de educacão, de inteligência e hábitos de consumo - uma visão que mais discrimina do que explica". Para ele, a cultura entendida sob uma perspectiva inclusiva pressupõe que "não existe ser humano sem cultura. É a cultura que humaniza o homem e permite a vida coletiva. Cultura, portanto, refere-se à maneira de viver total de um grupo, sociedade ou pessoa [...] a cultura está dentro e fora dos indivíduos [...] todas as formas culturais se equivalem enquanto diferentes modos de sentir, de celebrar, de pensar e de atuar sobre o mundo" (BARROS, 2003, p. 3). É de observar-se que os arquitetos se referem ao espaço enquanto uma entidade concreta e palpável, capaz de ser medido, manipulado e configurado. A maioria das pessoas percebe o espaço a partir de referentes simbólicos gerados a partir das formas de seu uso, apropriação e representação. Ou seja, a partir de suas práticas sociais. As representações se desenvolvem tanto no plano concreto como no imaginário. De modo simplificado e operativo, poderíamos compreender cultura como tudo que nos permite unir essas duas dimensões do espaço: o concreto e o simbólico. Ambas são interdependentes, integradas entre si. Nunca uma existe sem a outra, porque ambas são construções humanas. Como são os edifícios, a cidade e a paisagem.

(5) A perspectiva deste artigo se mantém fiel à visão da arquiteta Magnoli, para quem o "espaço pretérito é o espaço vazio [...] e, arquitetura é paisagem". Por isso cabe referir-se ao ensino de arquitetura em sua integridade, tal qual nos esclarece o arquiteto português João de Sousa Morais: "... toda atitude de construir no meio físico natural. Incide, portanto, sobre um conjunto muito alargado de técnicas e ciências afectas a outros profissionais de participação imprescindível, mas o arquitecto é aquele que vê, pensa e concebe como um todo [...] a arte de composição e construção dos edifícios para a comunidade, os diferentes usos de vida [...] ressaltam as regras identificáveis na Composição Arquitectónica [...] as codificações dos valores disciplinares da Arquitectura, que inicialmente é, inerente ao próprio processo construtivo, vai ganhando esporadicamente corpus teórico, só se autonomizando quando o acto projectual precede a realidade, representado-a virtualmente [...] os valores referidos, embora privilegiem o 
edifício e a cidade, vão também caracterizar permanências físicas, permitem-nos entender modelos, regras e modos de intervenção no espaço e no tempo. A identificação do sentido de um lugar ultrapassa, assim, largamente a identidade do edifício ou dos edifícios, sendo marcado pelo suporte físico alargado com todo o seu complexo sistema de valores" (MORAIS, 1995, p. 10-11, In: CHIESA; MENNA, 2005, p. 6).

(6) Dialogando com as idéias do paisagista francês Michel Corajoud (século XIX), "... o jardim não é feito para compensar as lacunas da cidade, nem para, simplesmente por ele, introduzir a natureza na cidade. O jardim na cidade é um fragmento de sonho, e não um enclave necessário para trazer o ar para o cidadão"; Miranda Magnoli agrega: "... também já não nos basta a compreensão da importância do espaço físico no modo de se estabelecerem as relações sociais: já avançamos na observação, na análise, de espaços em que, ao invés do - fragmento de sonho - de Corajoud, a organização dos espaços leva aos habitantes um cotidiano condicionador da reprodução de comportamentos tais que se reafirma a estrutura da formação social urbana existente" (MAGNOLI, 196, p. 14).

(7) A escola é, para Jean Claude Forquin, "um mundo social, que tem suas características próprias, seus ritmos e seus ritos, sua linguagem, seu imaginário, seus modos próprios de regulação e transgressão, seu regime próprio de produção e gestão de símbolos" - esta é a cultura da escola. Ela não deve ser confundida com a cultura escolar, "que se pode definir como o conjunto de conteúdos cognitivos e simbólicos que, selecionados, organizados, normatizados, rotinizados, sob o efeito dos imperativos de didatização, constituem habitualmente o objeto de uma transmissão deliberada no contexto das escolas" (In: CHIESA, 2001, p. 3).

(8) "Às mudanças com que, no país, de uma forma ou de outra, deveremos necessariamente nos deparar, cabe um lugar de destaque à pesquisa e aos núcleos de caráter científico; a elas caberá o avanço em um estágio mais complexo de produção do conhecimento; elas serão um fórum privilegiado para promover o debate e a difusão do trabalho coletivo, agregado em diversas Instituições e formações. Deveremos nos propor passos mais largos, de maior fôlego, em nossas pesquisas, em nossas reuniões, em nossa vontade de criar estímulos para atividades coletivas intermediárias de troca, de difusão, utilizando formas alternativas de comunicação." (MAGNOLI, 1996, p. 17)

(9) Pelo menos até a elaboração deste artigo. Tem-se conhecimento que o arquiteto Emmanuel Antonio dos Santos possui artigo no prelo, cujo conteúdo aborda aspectos importantes de sua pesquisa de doutorado. E também Sun Alex prepara edição de sua tese no formato de um livro. Já a pesquisa de Paulo Chiesa resultou na estruturação de subárea no âmbito da linha de pesquisas Cultura, Saberes e Escola do Programa de Pós-Graduação em Educação da UFPR (PPGE/UFPR). Até o presente foram defendidas três dissertações de mestrado. Outras duas dissertações de mestrado e uma tese de doutoramento estão em curso - todas elas investigando o ensino superior de arquitetura e de artes (dança e música) a partir da realidade acadêmica paranaense e catarinense.

(10) “...Um portulano é um livro de viagem: um relato de um percurso pela descrição detalhada e precisa de todos os elementos que possam interessar para alguém que pretenda uma viagem igual ou semelhante. É provável que os navegantes cristãos tivessem conhecimento da cartografia árabe, mas a eventual posse desses mapas, assim como os valiosos portulanos, eram segredos guardados a sete chaves pelos pilotos. James Clavell, faz uma vivida descrição deste segredo no seu romance Xogum". (CORDIVIOLA, 2005, p. 25)

(1 1) Quid Tum? É título de livro de Carlos Antônio Leite Brandão, pesquisa de extrema importância que resgata a figura de Leon Batista Alberti desde uma perspectiva filosófica, humana e cultural, enraizado nos problemas e conflitos de seu espaço-tempo. BRANDÃO, C. A. L. Quid Tum? O combate da arte na obra de Leon Batista Alberti. O termo significa, segundo o Vocabolario do Latin, de Ab Campanini i Carboni: "Quid novi? Che novità? Quid consilii? Che consiglio, disegno piano, partito, intenzione [...] Che allora = che questo, cos'è questo?"

\section{Bibliografia}

ALEX, Sun. Convívio e exclusão no espaço público: Questões de projeto de praças. 2004. 271 p. Tese (Doutorado) Faculdade de Arquitetura e Urbanismo, Universidade de São Paulo, São Paulo, 2004.

BARROS, José Marcio. Cultura, cidadania e desenvolvimento. In: Curso Cultura, Cidadania e Desenvolvimento. Ministrado no $12^{\circ}$ Festival de Inverno da UFPR. Antonina: 2003. 14 p. (xerox)

CHIESA, Paulo. O desenho como desígnio: Por uma ética do risco. 2001. 186 p. Tese (Doutorado) - Faculdade de Arquitetura e Urbanismo, Universidade de São Paulo, São Paulo, 2001.

CHIESA, Paulo; MENNA, Cláudio. Sistemas de espaços livres em Curitiba: Tradição, posturas e práticas locais. Curitiba: Programa Municipal Universidade da Cidade - IPPUC/UFPR, 2005. 34 p. (artigo inédito).

CORDIVIOLA, Alberto. Bahia - Tempo, cidade, arquitetura. 2005. 343 p. Tese (Doutorado) - Faculdade de Arquitetura e Urbanismo da Universidade Federal da Bahia, Salvador, 2005.

FORQUIN, Jean-Claude. Escola e cultura: As bases epistemológicas do conhecimento escolar. Porto Alegre: Artes Médicas Sul, 1993. 
GALENDER, Fany Cutcher. Produção em pesquisa do Grupo de Disciplinas Paisagem e Ambiente (GDPA) FAUUSP (1973 - julho 2003). Revista Paisagem e Ambiente - Ensaios, São Paulo: FAUUSP, n. 17, p. 123-21 1, 2003.

LEITE, Maria Angela Faggin Pereira. Destruição ou desconstrução: Questões da paisagem e tendências de regionalização. São Paulo: Hucitec/Fapesp, 1994.

MAGNOLI, Miranda Martineli. Experiência de Ensino de Paisagismo para Arquitetos na FAUUSP. In: Ensino e Pesquisa - Textos apresentados no IX CLEFA - Conferência Latino Americana de Escuelas y Facultades de Arquitectura, México, 1981. São Paulo: FAUUSP, 1981. p. 56- 76.

MAGNOLI, Miranda Martineli. Memorial. (Concurso para professor titular do Departamento de Projeto). 1987. 92 p. Faculdade de Arquitetura e Urbanismo, Universidade de São Paulo, São Paulo. 1987.

Espaços livres e urbanização. Apostila da Disciplina Aspectos da Paisagem Metropolitana - Programa de Pós-Graduação da Faculdade de Arquitetura e Urbanismo da Universidade de São Paulo. São Paulo: FAUUSP, 1983. $76 \mathrm{p}$.

. $O$ jardim na cidade é um fragmento de sonho. In: II ENCONTRO DE ENSINO DE PAISAGISMO EM ESCOLAS DE ARQUITETURA E URBANISMO NO BRASIL, 1994, São Paulo, Anais... São Paulo: Unimarco Editora: 1996. p. 13-18.

Palestra de abertura de Miranda Martinelli Magnoli. In: III ENCONTRO DE ENSINO DE PAISAGISMO EM ESCOLAS DE ARQUITETURA E URBANISMO NO BRASIL, 1996, São Carlos/SP. Anais, São Carlos, 07 p. (xerox)

Pesquisas em paisagem e ambiente. São Paulo, 2004. 15 p. (xerox - texto inédito).

MORAIS, João Sousa. Metodologia de projecto em arquitectura: Organização espacial na Costa Vicentina. Lisboa: Editoria Estampa, 1995.

SANTOS, Emmanuel Antonio dos. As paisagens do plano e os planos da paisagem: Da paisagem no planejamento ao planejamento com a paisagem. 2002. 206 p. Tese (Doutorado) - Faculdade de Arquitetura e Urbanismo, Universidade de São Paulo, São Paulo, 2002. 